\title{
Ergenlerin Sanal Zorbalık Düzeylerinin Bazı Değişkenler Açısından İncelenmesi
}

\author{
DOI: 10.26466/opus.515067 \\ * \\ Serhat Arslan $^{*}-$ Ferahim Yeşilyurt ${ }^{* *}$ \\ * Doç. Dr., Sakarya Üniversitesi, Eğitim Fakültesi, Hendek/Sakarya/ Türkiye \\ E-Posta: serhatarslan@sakarya.edu.tr \\ ORCID: 0000-0003-4422-8421 \\ ** Dr. Öğr. Üyesi, Fatih sultan Mehmet Vakıf Üniversitesi, Üsküdar/İstanbul/ Türkiye \\ E-Posta: ferahim1@gmail.com \\ ORCID: $\underline{0000-0003-2490-2685}$
}

\section{Öz}

Bu araştırmada ergenlerin sanal zorbalık düzeyleri açısından cinsiyet, sınıf, anne baba tutumu ve aile gelir düzeyi değişkenlerine göre farklılıklar olup olmadığının incelenmesi amaçlanmış̧ır. Araştırmanın çalışma grubunu, 2017-2018 eğitim-öğretim yılında, Ayază̆a Anadolu İmam Hatip Lisesi (İstanbul / Sarlyer), Hendek Anadolu Lisesi (Sakarya / Hendek), Bursa Atatürk Anadolu Lisesi (Bursa / Osmangazi) okulları içerisinde 9.sinıf,10.sinıf,11. Sinıf ve 12. Sinıflarında yer alan $326 \mathrm{kiz}, 393$ erkek olmak üzere toplamda 719 öğrenciden oluşmaktadır. Sanal zorbalık değişkeni için normallik testi Kolmogrov Smirnov testi ile kontrol edilmiştir. Bağımsız iki grup karşılaştırılmalarında sayısal değişkenlerin normal dağılım göstermediği durumlarda Mann Whitney U-Testi kullanılmıştır. Bă̆ımsız ikiden fazla grup için sayısal değişkenlerin normal dağ̊llım gösterdiği durumlarda Kruskal-Wallis testi kullanılmıştır. Istatistiksel analizler SPSS programı ile yapılmış ve istatistik analizlerde anlamlılık düzeyi 0.05 ( $p$ value) olarak dikkate alınmıştır. Araştırmada sanal zorbalık düzeyi açısından cinsiyete göre gruplar arasında kız öğrencilerin lehine istatistiksel açıdan anlamlı bir farklılık saptanmıştır. Ayrıca, aile tutumları düzeyi sanal zorbalık açısından farklılık göstermektedir. Aile tutumu düzeyi değişkenine göre anlamlı farklılığın Baskıcı -Koruyucu aile tutumu ile Baskıcı - Demokratik aile tutumları arasında olduğu sonucuna ulaşılmıştır. Ayrıca, ergenlerin sanal zorbalıkölçeğinden almış oldukları puanların, aile gelir düzeyi değişkenine göre anlaml farklılı̆̆ın yüksek gelir düzeyine sahip aileye sahip ergenler ile orta gelir düzeyine sahip ergenlerin aileleri arasında olduğu sonucuna ulaşılmıştır. Ergenlerin sanal zorbalık ölçeğinden almış oldukları puanların, sınıf düzeyi değişkenine göre anlamlı bir şekilde farklılaşıp farklılaşmadığını belirlemek üzere yapılan analiz sonucunda, gruplar arasında istatistiksel açıdan anlamlı bir farklılık saptanmamıştır. Bulgular kavramlarla ilgili alan yazınında edinilen bilgiler ışığında tartışılmıştır ve bulguların ileride bu alanda yapılacak olan çalışmalara ışık tutacak nitelikte olduğ $u$ düşünülmektedir.

Anahtar Kelimeler: Sanal zorbalık, zorbalık, ergenlik 


\title{
Examination of The Levels of Cyber Bullying of Adolescents in Terms of Some Variables
}

\begin{abstract}
In this study, it is aimed to examine the levels of cyber bullying of adolescents and to find out whether there are any differences in terms of gender, class, parental attitude and family income level. Study group comprise of 719 high school students (450 females, 197 males). The Kolmogorov Smirnov test was used to test the normality of the variables for virtual bullying. The Mann Whitney U-test was used to compare the two independent groups in cases where the numerical variables were not normality distribute. Kruskal-Wallis test was used in cases where numerical variables were normally distributed for more than two independent groups. Statistical analysis was performed using SPSS program and statistical analysis was taken into consideration as p-value. In this study, there was a statistically significant difference between the groups in terms of the level of cyber bullying in favor of female students in terms of gender. In addition, values in terms of family attitudes differ in terms of cyber bullying. It was concluded that significant differences were found between repressive and protective family attitudes and repressive and democratic family attitudes according to the family attitude level variables. In addition, it was concluded that adolescents' scores from the cyber bullying scale were significantly different from those of families with high income levels and families with middle income. As a result of the analysis conducted to determine whether the scores of adolescents obtained from the cyber bullying scale differed significantly by the class level variable, no statistically significant difference was found between the groups. The findings are discussed in the light of the information obtained in the literature about the concepts and it is thought to shed light on the works to be done in this field in the future.
\end{abstract}

Keywords Cyber bullying, bullying, adolescents 


\section{Giriş}

Eğitim ortamında öğrencilerin karşılaştığı zorbalık davranışları son yıllarda çözüm bekleyen sorunsallar arasında yer almaktadır. Zorbalık davranışı, Bronfenbrenner'ın Ekolojik Teorisi, mikro, mezzo ve makro düzeylerindeki zorbalık davranışlarının araştııılması için bir temel olarak kullanılmıştır. Bu ortamlar arasındaki etkileşimin de ergenlerin demografik ve aile yapısı tarafından etkilendiği düşünülmektedir. Bu fikir, sorunların sadece çocukların ya da çevrelerinin bireysel özelliklerine göre değil, ikisi arasındaki etkileşimlerin bir sonucu olarak ortaya çıtığını göstermektedir (Hong ve Eamon, 2012). Zorbalık üzerine yapılan araştırmalar, zorba davranışların yanı sıra mağduriyetin bireyler, aileler, sosyal görünüm, toplum ve akranlar arasındaki etkileşim gibi birçok etkenden oluştuğunu göstermiştir. Ekolojik teori ile zorbalık davranışlarl; akranın çevresi, arkadaşları, öğretmenin tepkisi, kültürü ve toplum tarafından da etkilendiğini açıklamaktadır (Swearer ve Doll, 2001).

Olweus (1995), zorbalığı zihinsel ve / veya fiziksel olarak tekrar eden "şiddet veya baskı" olarak tanımlamıştır. Ayrıca, zorbalığın, bir ya da daha fazla insanın sürekli olarak olumsuz eylemlere maruz kalmasının, kurbanın güç dengesizliği nedeniyle kendisini savunmasını zorlaştırdığı durumlarda meydana geldiğini belirtmektedir. Ayrıca, bir eylemin zorbalık olarak adlandırılabilmesi için; kasıtlı olarak zarar vermeyi amaçlaması, süreklilik özelliği göstermesi ve zorba ile mağdur arasında güç dengesizliğinin olması gerekmektedir (Yaman,Eroğlu ve Peker, 2011).

Zorbalık davranışları; zorba ile mağdur arasındaki güç dengesizliğine dayanan ve tekrarlayan bir saldırganlık alt kümesi olarak tanımlamıştır (Craig ve diğ., 2007). Zorbalık davranışları arasında doğrudan fiziksel saldırganlık, doğrudan sözlü saldırganlık ve dolaylı saldırganlık yer almaktadır. Zorbalık, gücün zarar verme ve dengesizliğine yönelik özellikleri artıran bir tür eş mağduriyettir. Zorbalık, çoğunlukla, zarar vermek veya sıkıntıya neden olmak için (fiziksel, psikolojik veya duygusal) kullanılan tekrarlanan, saldırgan ve kasıtlı bir davranış olarak tanımlanır ( $\mathrm{O}^{\prime}$ Connell ve diğ.., 1999). Davranış, kurban ve mağdur arasında güç dengesizliği içermelidir. Algılanan (ya da gerçek) güç dengesizliği genellikle fiziksel boyut ya da güç, popülerlik durumu, zeka ya da bir yetersizlik formu ile 
ortaya çıkmaktadır. Ayrıca, davranış zaman içinde tekrar tekrar oluşmalıdır. Davranışın tekrarı, kurban ve zorba arasındaki ilişkide daha büyük bir eşitsizlik yaratabilir ve mağdurun rahatsız hissetmesinden kaçınmasını daha da zorlaştırabilir (Craig ve diğ., 2007; O'Connell ve diğ..., 1999).

Teknolojinin gelişmesiyle kullanılan bilgisayar, cep telefonu, tablet gibi iletişim araçlarının kullanılış biçimlerinde de farklılıklar gözlenmeye başlamıştır. Bu durum özellikle ergenlik dönemindeki bireylerde ve çocuklarda gözlemlenen davranış biçimlerinde farklılıklara neden olmaktadır. Bir çok bilgiye rahatlıkla ulaşabilme, duygularını ve düşüncelerini diğerlerine rahatlıkla ifade edebilme ve sanal ortamda arkadaşlık kurma olanağı sağlamaktadır. Bu rahatlık içerisine giren bireyler yalan söyleme, tahrik ve taciz etme gibi birçok farklı davranışlar sergileyerek istenilmeyen davranışlar göstermektedirler (İlhan, 2016).

Arıcak (2011) sanal zorbalığı, bilgi ve iletişim teknolojilerini kullanarak bir birey ya da gruba, özel ya da tüzel bir kişiliğe karşı yapılan teknik ya da ilişkisel tarzda zarar verme davranışlarının tümü olarak tanımlamaktadır. Bu bağlamda sanal zorbalık; birinin e-posta ya da cep telefonuna mesaj ya da e-posta gönderme, metin mesajlarıyla ya da internet üzerinden dedikodu yayma, sosyal paylaşım sitelerine veye internet sitelerine tehdit edici veya incitici mesajlar gönderme, birinin hesap bilgilerini çalma, başkalarını incitmek için başka biriymiş gibi davranma, birinin uygunsuz görüntülerini cep telefonu veya internet üzerinden yayma gibi zararlı eylemlerin tümünü kapsamaktadır. Sanal zorbalık, elektronik iletişim araçları ile yapılan çevrim içi saldırganlığın bir biçimi olarak da tanımlanmaktadır. Bir eylemin sanal zorbalık olarak adlandırılabilmesi için; davranışın önceden tasarlanması, zorba davranışın süreklilik göstermesi, zarar verme amacı ve elektronik araçların kullanılmasını içermektedir (Yaman, Eroğlu ve Peker, 2011).

Zorba / mağdur olan bireyler, daha yüksek düzeyde psikososyal uyumsuzluk ve davranış sorunları nedeniyle en "sorunlu grup" olarak tanımlanmışlardır. Kurban/ Zorba bireylerde; yüksek düzeyde depresyon ve problem davranışları içeren düşük öz-denetim ve sosyal yeterliliğin yanında okulda başarısızlık davranışları görülmektedir (Nansel ve diğ., 2001). Bazı yönlerden sanal zorbalık ile geleneksel zorbalık arasında benzerlikler yer almaktadır. Bu benzerlikler; tehdit, alay etme, aşağılama, kü- 
çük düşürme olarak sınıflandırılabilir. Bu duruma ek olarak, sanal zorbalık fiziksel güç gerektirmediği için, normalde fiziksel olarak saldırgan davranışlarda bulunmayan kişilerin başkaları üzerinde güç ve kontrol elde etmek için kullanabilecekleri bir yol olabilir. Sanal zorbalık, özellikle çevrimiçi zorbalığın akranlar tarafından gözlemlenmesi durumunda, bireylerin daha yüksek sosyal statü elde etmeyi amaçladıkları bir yol olabilir. Yüz yüze zorbalığa uğrayan mağdurlar, interneti başkalarına hükmetme ya da iktidarı yeniden ele geçirme ve onları kontrol altına almak için faillerine misilleme yapma yolu bulabilirler (Pellegrini, 2002). Sanal zorbalar internet veya cep telefonunda saldırgan davranışları benlik saygısını eski haline getirme, düzenleme veya geliştirmenin bir yolu olarak yapabilir. Sanal zorbalık, giderek artan bir şekilde zorba ve kurban içeren daha büyük kitlelere ulaşma potansiyeline sahiptir. Yüz yüze zorbalıkla mağdur, kendisine ya da onlar hakkında söylenen tüm olumsuz şeyleri hatırlamayabilir. Sanal zorbalıkta zorba davranış soyut bir şekilde yapılmaktadır. Online ortamda bir kere zorba davranış paylaşılırsa tekrar silinmesi imkânsız hale gelebilmektedir. Sanal zorba olarak etikenlenmek zorbalar için uzun vadeli sonuçlara sahiptir. İlkokulda zorba olarak etiketlenen çocuklar gelecekte daha fazla psikolojik desteğe ihtiyaç duyabilir, madde kullanımına sebep olabilir, anti sosyal kişilik bozukluğu ve ruh sağlığı hizmetlerini daha fazla kullanabilmektedir. Sanal zorbalık, uyuşturucu kullanımı ve suç faaliyeti gibi akranlar tarafından kabul edilmeye çalışılan ergenler tarafından her türlü kendine zarar verici davranışa yol açabilir ve ölümcül sonuçlara yol açabilir (Badiuk, 2006). Ayrıca, sanal zorbalığın görülme biçimleri ;online kavga, çevrim içi zarar verme, iftira atma, başka bir kimliğe bürünme, başkalarının bilgilerini internet ortamında izinsiz kullanma, çevrim içi dışlama, sanal taciz, sanal tehdit davranışlar olarak tanımlanmıştır (Yaman,Eroğlu ve Peker, 2011). Bu araştırmanın amacı ergenlerin sanal zorbalık düzeyleri açısından cinsiyet, sınıf, anne baba tutumu ve aile gelir düzeyi değişkenlerine göre farklılıklar olup olmadığının incelenmesidir. 


\section{Yöntem}

\section{Araştırma Modeli}

Çalışmada, nicel araştırma deseninden betimsel tarama modeline başvurulmuştur. Betimsel tarama modeli; geçmişte veya içinde bulunduğumuz dönemde de varlığını devam ettiren durumu olduğu gibi yansıtmayı amaçlayan bir araştırma modelidir (Karasar, 2006).

\section{Çalışma Grubu}

Araştırmanın çalışma grubu, 2017-2018 eğitim-öğretim yılında, Ayazağa Anadolu İmam Hatip Lisesi (İstanbul / Sarıyer), Hendek Anadolu Lisesi (Sakarya / Hendek), Bursa Atatürk Anadolu Lisesi (Bursa / Osmangazi) okulları içerisinde 9.sınıf,10.sınıf,11. Sınıf ve 12. Sınıflarında yer alan 326 kız, 393 erkek olmak üzere toplamda 719 öğrenciden oluşmaktadır. Öğrencilerin sınıf düzeylerine bakıldığında ise, 242'si (\%33.7) 9.sınıf, 136's1 (\%18.9) 10.sınıf, 174'ü 11.sınıf (\%24.2) ve 167'si (\%23.2) 12.sınıf olarak tespit edilmiştir. Tablo 1'de katılımcıların demografik özellikleri verilmiştir.

\section{Veri Toplama Araçları}

Araştırmanın veri toplama sürecinde genel ve psikometrik özellikleri verilen Kişisel Bilgi Formu, Sanal Zorbalık Ölçeği (SZÖ) kullanılmıştır.

Ergenlerde Sanal Zorbalık Ölçeği: Álvarez-García, Barreiro-Collazo, Nú̃nez, ve Dobarro (2016) tarafından geliştirilen ergenlerde sanal zorbalık ölçeğinin araştırmacı tarafından Türkçe uyarlaması yapılmıştır. Ölçek uyarlama çalışması kapsamında, güvenirlik, madde analizi düzeltilmiş madde-toplam puan korelasyonu ve doğrulayıcı faktör analizleri yapılmıştır. Ölçeğin güvenirlik katsayısı (Cronbach alfa) .89 olarak bulunmuştur. Ölçeğin açımlayıcı faktör analizi sonucunda, Kaiser-Meyer-Olkin örneklem yeterliliği .92 bulunmuştur. Ölçeğin üç faktörlü yapısının toplam varyansı açıklaması \% 57 olarak bulunmuştur. Ölçek için yapılan doğrulayıcı faktör analizinde üç boyutlu modelin iyi uyum verdiği görülmüştür 
$\left(x^{2}=600.31, \mathrm{sd}=87, \mathrm{p}=0.00, \mathrm{RMSEA}=.085, \mathrm{NFI}=.95, \mathrm{NNFI}=.95, \mathrm{CFI}=.96\right.$, $\mathrm{IFI}=.96$, RFI=.94, GFI=.91, ve SRMR=.30). Yapilan analiz sonucunda, ergenlerde sanal zorbalık ölçeği Türkçe Formunun uygulandığı örneklem grubunda geçerli ve güvenilir olduğu sonucuna ulaşılmıştır. Ölçeğin madde toplam korelasyonları ve yapısal eşitlik modellemesine yönelik bulgular sunulmuştur.

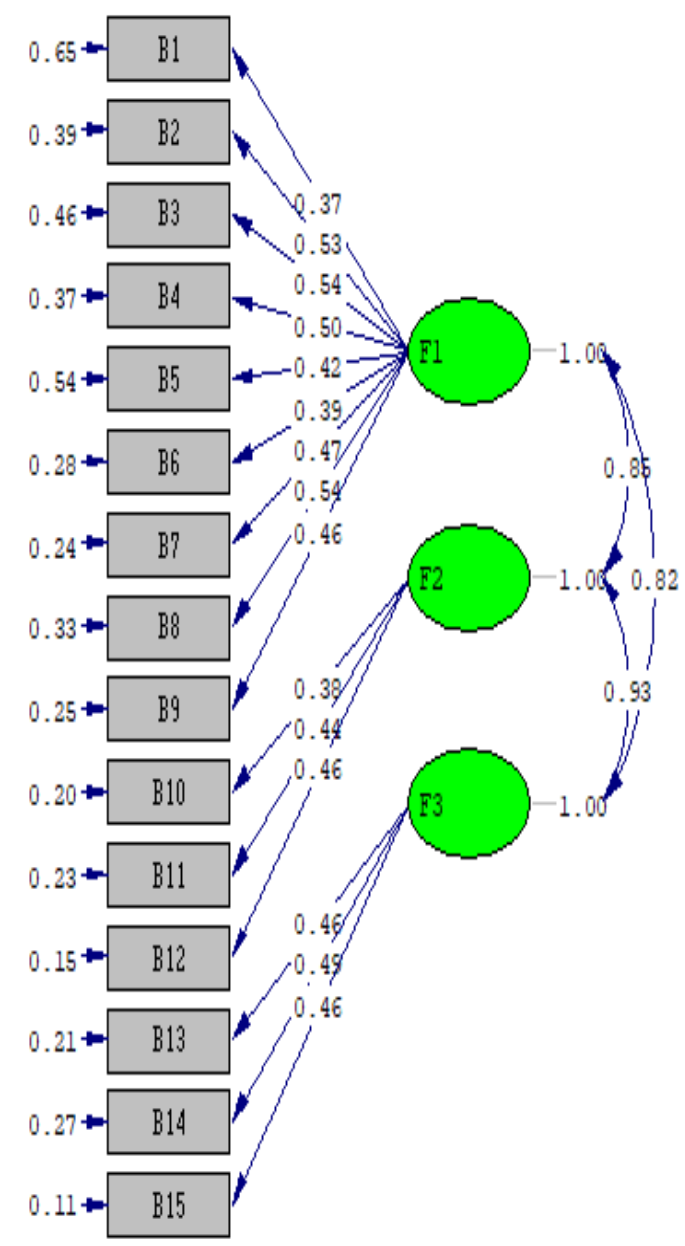

Chi-Square $=600.31, d f=87, \mathrm{p}-\mathrm{value}=0.00000, \mathrm{RUSEA}=0.085$

Şekil 1. Ergenlerde Sanal Zorbalık Ölçeği Yapısal Eşitlik Modellemesi 


\section{Bulgular ve Yorum}

Ergenlerin sanal zorbalık değişkenine yönelik betimsel istatistikleri Tablo 1 de verilmiştir.

Tablo 1. Ergenlerin Cinsiyetlerine Göre Sanal Zorbahk Düzeylerine İlişkin Mann Whitney U-Testi tablosu

\begin{tabular}{|c|c|c|c|c|c|c|c|c|}
\hline Cinsiyet & & $\mathbf{N}$ & Sira Ort. & Sira Top & MWU & W & Z & $\mathrm{p}$ \\
\hline \multirow{2}{*}{ Sanal Zorbalık } & Kız & 326 & 394,8 & 128729 & 5268 & 130110 & -4.13 & 00 \\
\hline & Erkek & 393 & 331,0 & 130110 & & & & \\
\hline
\end{tabular}

Analiz sonucunda Tablo 1 de, ergenlerin sanal zorbalık ölçeğinden almış oldukları puanların, cinsiyet değişkenine göre anlamlı bir şekilde farklılaşıp farklılaşmadığını belirlemek üzere yapılan non-parametrik Mann Whitney-U testi sonucunda, gruplar arasında kız öğrencilerin lehine istatistiksel açıdan $\mathrm{p}<0.05$ düzeyinde anlamlı bir farklılık saptanmıştir.

Ergenlerin sanal zorbalık ölçeği sınıf değişkenine göre analiz sonuçları Tablo 2 de verilmiştir.

Tablo 2. Kruskal-Wallis Testi sonucu

\begin{tabular}{|c|c|c|c|c|c|c|}
\hline & \multirow[b]{2}{*}{ Sinıf Düzeyi } & \multirow[b]{2}{*}{$N$} & \multirow[b]{2}{*}{ Sira Ort. } & \multicolumn{3}{|c|}{ Kruskal Wallis Testi } \\
\hline & & & & KiKare & $S d$ & $p$ \\
\hline \multirow{4}{*}{ 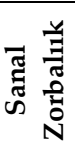 } & 9. Sinif & 242 & 365.7 & \multirow{4}{*}{5.9} & \multirow{4}{*}{3} & \multirow{4}{*}{.114} \\
\hline & 10. Sinif & 136 & 322.3 & & & \\
\hline & 11. Sinif & 174 & 376.5 & & & \\
\hline & 12. Sinif & 167 & 365.1 & & & \\
\hline
\end{tabular}

Analiz sonucunda gruplar arasında sanal zorbalık ölçeği sınıf değişkeni istatistiksel açıdan $p>0.05$ düzeyinde anlamlı bir farklılık saptanmamiştır.

Ergenlerin Aile genel Tutumu Değişkenine Göre Sanal Zorbalık Kruskal Wallis Testi sonuçları Tablo 3 de verilmiştir. 
Tablo 3. Ergenlerin Aile genel Tutumu Değişkenine Göre Sanal Zorbalık Kruskal Wallis Testi sonuçları

\begin{tabular}{|c|c|c|c|c|c|c|}
\hline & \multirow[b]{2}{*}{ Aile tutumu } & \multirow[b]{2}{*}{$N$} & \multirow[b]{2}{*}{ Sira Ort. } & \multicolumn{3}{|c|}{ Kruskal Wallis Test } \\
\hline & & & & KiKare & $S d$ & $p$ \\
\hline \multirow{4}{*}{ 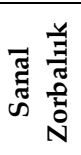 } & Koruyucu & 445 & 339 & \multirow{4}{*}{24.2} & \multirow{4}{*}{3} & \multirow{4}{*}{.00} \\
\hline & Baskıc1 & 113 & 438 & & & \\
\hline & İlgisiz & 42 & 410 & & & \\
\hline & Demokratik & 119 & 344 & & & \\
\hline
\end{tabular}

Analiz sonucunda gruplar arasında istatistiksel açıdan $\mathrm{p}<0.05$ düzeyinde anlamlı bir farklılık saptanmıştır. Anlamlı farklılığın hangi gruplar arasında olduğunu belirlemek için varsyanların eşit olmadığı durumlarda kullanılan Tamhane testi sonuçları ve betimsel istatistik sonuçları Tablo 4 de yer almaktadır.

Tablo 4: Ergenlerin Aile genel Tutumu Değişkenine açısından Sanal zorbalık düzeyleri Tamhane testi sonuçları

\begin{tabular}{|c|c|c|c|c|c|c|}
\hline \multirow{2}{*}{\multicolumn{2}{|c|}{$\begin{array}{l}\text { Aile genel Tutumu } \\
\text { Değişkenine }\end{array}$}} & \multirow{3}{*}{$\begin{array}{l}\begin{array}{l}\text { Ortalama fark } 1 \\
\text { (I-J) }\end{array} \\
-2,75959^{*}\end{array}$} & \multirow{3}{*}{$\begin{array}{l}\begin{array}{l}\text { Standart } \\
\text { sapma ha- } \\
\text { tasi }\end{array} \\
72782\end{array}$} & \multirow{3}{*}{$\begin{array}{l}\mathbf{p} \\
, 001\end{array}$} & \multicolumn{2}{|c|}{ \% 95 Güven Aralığı } \\
\hline & & & & & $\begin{array}{l}\text { Alt Sinır Üst S1- } \\
\text { nir }\end{array}$ & Alt Sınır Üst Sınır \\
\hline \multirow[t]{3}{*}{1} & 2 & & & & $-4,6993$ &,- 8198 \\
\hline & 3 & $-1,07164$ & ,98636 & 864 & $-3,7764$ & 1,6331 \\
\hline & 4 & 06981 & 62601 & 1,000 & $-1,5951$ & 1,7348 \\
\hline \multirow[t]{3}{*}{2} & 1 & $2,75959^{*}$ & ,72782 & ,001 & ,8198 & 4,6993 \\
\hline & 3 & 1,68795 & 1,15798 & 619 & $-1,4315$ & 4,8074 \\
\hline & 4 & $2,82940^{*}$ & 87172 & ,008 &, 5151 & 5,1437 \\
\hline \multirow[t]{3}{*}{3} & 1 & 1,07164 & ,98636 & 864 & $-1,6331$ & 3,7764 \\
\hline & 2 & $-1,68795$ & 1,15798 & 619 & $-4,8074$ & 1,4315 \\
\hline & 4 & 1,14146 & 1,09685 & 884 & $-1,8264$ & 4,1093 \\
\hline \multirow[t]{3}{*}{4} & 1 &,- 06981 & 62601 & 1,000 & $-1,7348$ & 1,5951 \\
\hline & 2 & $-2,82940^{*}$ & 87172 & ,008 & $-5,1437$ &,- 5151 \\
\hline & 3 & $-1,14146$ & 1,09685 & 884 & $-4,1093$ & 1,8264 \\
\hline
\end{tabular}

Tablo 4 incelendiğinde ergenlerin sanal zorbalık ölçeğinden almış oldukları puanların, aile tutumu düzeyi değişkenine göre anlamlı farklılığın Baskıcı (2)-Koruyucu (1) aile tutumu ile Baskıcı (2)- Demokratik (4) aile tutumları arasında olduğu sonucuna ulaşılmıştır. Baskıcı aile sıra ortalamalarının istatistiki anlamda yüksek olduğu bulunmuştur. 
Ergenlerin Sanal Zorbalık Düzeylerine Göre Aile Gelir Değişkenine İlişkin Bulgular Tablo 5 de verilmiştir.

Tablo 5 . Ergenlerin Sanal Zorbalık Düzeylerine Göre Aile Gelir Değişkenine İlişkin Bulgular

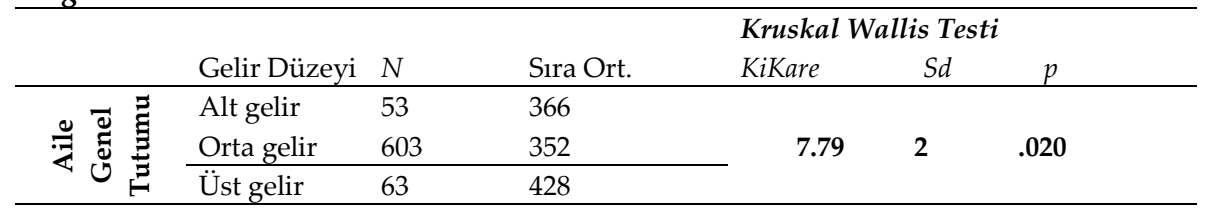

Analiz sonucunda gruplar arasında istatistiksel açıdan $p<0.05$ düzeyinde anlamlı bir farklılık saptanmıştır. Anlamlı farklılığın hangi gruplar arasında olduğunu belirlemek için varyansların eşit olmadığı durumlarda kullanılan Tamhane testi sonuçları Tablo 6 da yer almaktadır.

Tablo 6: Ergenlerin Sanal Zorbalık Düzeylerine Göre Aile Gelir Değişkenine İlişkin Tamhane testi sonuçları

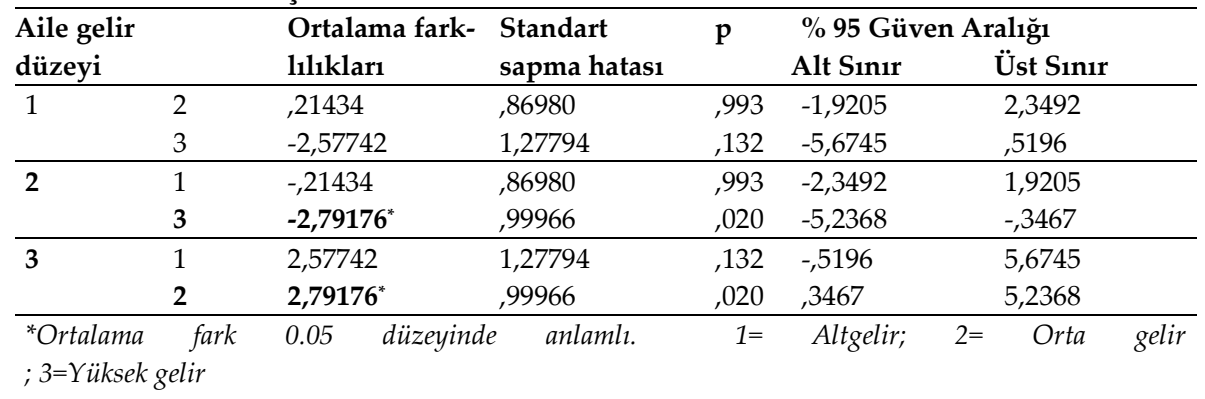

Tablo 6 incelendiğinde ergenlerin sanal zorbalık ölçeğinden almış oldukları puanların, aile gelir düzeyi değişkenine göre anlamlı farklılığın Yüksek gelir düzeyine sahip aileye sahip ergenler ile (3)-Orta gelir düzeyine sahip ergenlerin aileleri (2) arasında olduğu sonucuna ulaşılmıştır. Yüksek aile gelir düzeyine sahip ergenlerin sıra ortalamalarının istatistiki anlamda yüksek olduğu bulunmuştur. 


\section{Sonuç, Tartışma ve Öneriler}

Ergenlerin sanal zorbalık ölçeğinden almış oldukları puanların, cinsiyet değişkenine göre anlamlı bir şekilde farklılaşıp farklılaşmadığını belirlemek üzere yapılan analiz sonucunda, gruplar arasında kız öğrencilerin lehine istatistiksel açıdan anlamlı bir farklılık saptanmıştır.

Keith ve Martin (2005) sanal zorbalığın cinsiyete göre farklılaştığını ve kızların erkeklerden daha sanal zorba olduğu sonucuna ulaşmıştır. Bu sonuçlar araştırmanın bulgularını destekler niteliktedir. Bu araştırmanın bulguları kız öğrencilerin erkeklerden daha fazla sanal zorbaca davranışlar gösterdiklerini göstermektedir. Kız öğrencilerin erkeklerden daha fazla sanal mağdur olduğunu savunan araştırmalar da vardır (Slonje ve Smith, 2008).

Ergenlerin sanal zorbalık ölçeğinden almış oldukları puanların, sınıf düzeyi değişkenine göre anlamlı bir şekilde farklılaşıp farklılaşmadığını belirlemek üzere yapılan analiz sonucunda anlamlı bir farklılık saptanmamıştır. Sınıf düzeyi değişkeninin ergenlerin sanal zorbalık düzeylere etkisi olmadığ1 yönünde alanyazında yer alan çalışmalar vardır. Soydaş (2011), yapmış olduğu çalışmada sınıf düzeyinde, zorbalık uygulama açısından anlamlı bir farklılık olmadığı görülürken, zorbalığa maruz kalmada anlamlı bir farklılık olduğu bulunmuştur. Bu sonuçlar araştırmanın bulgularını destekler niteliktedir.

Ergenlerin sanal zorbalık ölçeğinden almış oldukları puanların, aile tutumu düzeyi değişkenine göre anlamlı bir şekilde farklılaşıp farklılaşmadığını belirlemek üzere yapılan analiz sonucunda, anlamlı farklılığın Baskıcı -Koruyucu aile tutumu ile Baskıc1 - Demokratik aile tutumları arasında olduğu sonucuna ulaşılmıştır. Baskıcı aile tutumu sıra ortalamalarının istatistiki anlamda yüksek olduğu bulunmuştur. Ergenlerin ebeveynleri ile olan ilişkileri, ebeveyn tutumları, sanal zorbalık üzerinde etkisi yaşanılan çevreye, akranlarla olan ilişkilere, ebeveynlerin sınır koyma, denetleme, ilgi gösterme gibi faktörleri içeren aile tutumlarına göre şekillenmektedir. Türkileri (2012) yapmış olduğu çalışmada, aile tutumunun, arkadaş çevresinin ve yaşanılan çevrenin gencin sanal zorbalık türü davranışlarda bulunmasında belirleyici olarak yer aldığını ifade etmiştir. Bu sonuçlar araştırmanın bulgularını destekler niteliktedir. 
Ergenlerin sanal zorbalık ölçeğinden almış oldukları puanların, aile gelir düzeyi değişkenine göre anlamlı bir şekilde farklılaşıp farklılaşmadığını belirlemek üzere yapılan analiz sonucunda anlamlı bir farklılık saptanmıştır. Aile gelir düzeyi değişkenine göre anlamlı farklılığın yüksek gelir düzeyine sahip aileye sahip ergenler ile orta gelir düzeyine sahip ergenlerin aileleri arasında olduğu sonucuna ulaşılmıştır. Ciminli (2016), Öğrencilerin ailenin gelir durumuna göre sanal zorbalık puanlarına ilişkin analiz sonuçları öğrencilerin ailenin gelir durumuna göre sanal zorbalık puanlarının anlamlı ölçüde farklılaştığını göstermektedir.

Araştırmanın sonuçları değerlendirilerek şu önerilerde bulunulabilir: Bu çalışmada öğrencilerin sanal zorbalık düzeyleri ölçme araçları aracılığ ile toplanan veriler yardımı ile ele alınmıştır. Farklı değişkenler ele alınarak yapılacak olan çalışmalar, sanal zorbalığı etkileyen etmenleri belirleme açısından faydalı olabilir. Araştırmada nicel veriler kullanılmıştır. Yapılacak nitel çalışmalar sanal zorbalığın altında yatan etmenleri belirlemede önemli katkı sağlayabilir. Okul yöneticilerine, öğretmenlere, ailelere ve öğrencilere gelişen teknolojik ilerlemeler kapsamında sorumlu bir şekilde ve etik değerlere uygun olarak kullanmaların öğrenmeleri için hizmet içi eğitimler düzenlenebilir. Sanal zorbalığın önlenmesi açısından aileler; örnek olma, kurallar koyma ,filtre programlar uygulama, sanal zorbalığa maruz kalındığın rahatlıkla aile ile iletişime geçme, çevrimiçi davranış kuralları anlaşması yapılması sağlanabilir. 


\title{
EXTENDED ABSTRACT
}

\section{Examination of The Levels of Cyber Bullying of Adolescents in Terms of Some Variables}

*

\author{
Serhat Arslan - Ferahim Yeşilyurt \\ Sakarya University - FSM Vakif University
}

Bullying behavior encountered by students in the educational environment is among the problems awaiting solutions in recent years. Bullying behavior, the ecological theory of Bronfenbrenner, was used as a basis for investigating bullying behavior at micro, mezzo and macro levels. The interaction between these environments is also thought to be influenced by the demographic and family structure of adolescents. This idea shows that problems arise not only as a result of individual characteristics of children or their environment, but also as a result of interactions between the two. Research on bullying has shown that in addition to bullying behavior, victimization consists of many factors, such as individuals, families, social appearance, society and interaction between peers. Ecological theory and bullying behavior; peer environment, friends, teacher's reaction, culture and society are affected by explains. Olweus described violence as "violence or repression," which mentally and / or physically repeated. Olweus also states that bullying occurs when one or more people are constantly exposed to negative actions, making it difficult for the victim to defend himself because of the power imbalance. In addition, in order for an action to be called bullying, it is necessary to purposefully cause harm, to show a permanent nature, and to have a balance of power between bullying and victimization. Bullying / victim individuals are defined as the most problematic group because of higher levels of psychosocial incompatibility and behavioral problems. Victim/ Bully individuals; in addition to low selfcontrol and social competence, which includes high levels of depression and problem behaviors, failure behaviors are observed in school. In some ways, there are similarities between cyber bullying and traditional bullying. These similarities can be classified as threats, mockery, humiliation, humiliation. The aim of this study was to investigate whether there were 
differences between gender, class, parents attitude and family income levels in terms of adolescents ' cyber bullying levels. In this study, a descriptive scanning model was applied from quantitative research pattern. Sample of the research, in 2017-28 academic year, Ayazaga Anatolian Imam Hatip High School (Istanbul / Sariyer), Hendek Anatolian High School (Sakarya / Hendek), Bursa Atatürk Anatolian High School (Bursa / Osmangazi). As a result of the analysis conducted to determine whether the scores of adolescents received from the scale of cyber bullying were significantly different than the gender variables, there was a statistically significant difference between the groups in favor of girls ' students. Keith and Martin (2005) concluded that cyber bullying differs from gender and that girls are more cyber bullying than boys. These results support the findings of the study. The findings of this study show that girls have more cyber bullying behavior than boys. There are also research that argues that girl students are more cyber victims than boys. The results of the analysis conducted to determine whether the scores of adolescents received from the scale of cyber bullying were significantly different than the class level variables did not differ significantly. There are studies in the literature that the class level variable has no effect on the cyber bullying levels of adolescents. In this study, it was found that there was no significant difference in the class level in terms of bullying practice, whereas there was a significant difference in the exposure to bullying. These results support the findings of the study. The results of the analysis conducted to determine whether the scores of adolescents received from the cyber bullying scale differ significantly from the family attitude level variable, concluded that significant differences were among repressive-protective family attitudes and repressive - democratic family attitudes. It was found that the pressure family attitude averages were high in terms of statistical significance. The relationship of adolescents with their parents, parental attitudes, the environment having an impact on cyber bullying, relationships with peers, parents ' boundaries, control, showing interest, such as factors are shaped according to family attitudes. Also stated that the family attitude, the friend environment and the environment of the young person were the determining factors in the conduct of cyber bullying. These results support the findings of the study. A significant difference was found in the results of the analysis to determine whether the scores of adolescents 
received from the cyber bullying scale were significantly different from the family income level variables. According to the family income level variable, it was concluded that the difference was between the families of adolescents with high incomes and the families of adolescents with middle income. Ciminli, analysis results on cyber bullying scores according to the income status of the students show that the cyber bullying scores differ significantly from the income status of the students. The results of the study can be evaluated and suggested as follows: in this study, the students ' cyber bullying levels are discussed with the help of the data collected through the measurement tools. Different variables can be used to determine the factors that affect cyber violence. Quantitative data were used in the research. Qualitative studies can contribute to determining the underlying factors of cyber bullying. In-service training can be arranged for school administrators, teachers, families and students to learn to use them responsibly and in accordance with ethical values within the scope of the technological progress that develops. In order to prevent cyber bullying, families can be provided with an example,setting rules, applying filter programs, communicating with the family easily when you are exposed to cyber bullying, and online conduct rules agreement.

\section{Kaynakça / References}

Arıcak, O. T. (2011). Sanal zorbalık: Gençlerimizi bekleyen yeni tehlike. Kariyer Penceresi, 2(6), 10-12.

Ciminli, A. (2016). Ergenlerde sanal zorbalık ve mağduriyetin empati ve kişilik özellikleriyle ilişkisinin incelenmesi. Erzincan Üniversitesi, Sosyal Bilimler Enstitüsü, Yüksek Lisans Tezi, Erzincan.

Craig, W. M., Pepler, D. J., ve Blais, J. (2007). Responding to bullying: What works? International Journal of School Psychology, 28, 15-24.

Hong, J. S. ve Eamon, M. K. (2012). Students' perceptions of unsafe schools: An ecological systems analysis. Journal of Child ve Family Studies, 21, 428-438.

İlhan, A.Ü. (2016). Ortä̈̆gretim öğrencilerinin sanal zorbalık ve internet saldırganlık düzeyleri ile sosyal medyaya ilişkin tutumlarmm incelenmesi (Çekmeköy Örneği). Yeditepe Üniversitesi Eğitim Bilimleri Enstitüsü, Yüksek Lisans Tezi, İstanbul. 
Keith, S., ve Martin, M. E. (2005). Cyber-bullying: Creating a culture of respect in a cyber world. Reclaiming Children and Youth, 13, 224228.

Nansel, T. R., Overpeck, M., Pilla, R. S., Ruan, W. J., Simons-Morton, B., ve Scheidt, P. (2001). Bullying behaviours among us youth: Prevalence and associations with psychosocial adjustment. Journal of the American Medical Association, 255(16), 1094-2100.

Olweus, D. (1995). Bullying or peer abuse at school: facts and intervention. Current Directions in Psychological Science, 4(6), 196-200.

Pellegrini, A. D. (2002). Bullying, victimization, and sexual harassment during the transition to middle school. Educational Psychologist, 37(3), 151-163.

Slonje, R. ve Smith, P. (2008). Cyberbullying: Another main type of bullying? Scandinavian Journal of Psychology,49,147-154.

Soydaş, D.K. (2011). Ergenlerde ebeveyn izlemesi, sanal zorbalık ve yaşam doyumu arasındaki ilişkilerin cinsiyete göre incelenmesi. Hacettepe Üniversitesi, Gelişim Psikolojisi Bilim Dalı,Yüksek lisans tezi.

Swearer, S. M., ve Doll, B. (2001). Bullying in schools: An ecological framework. Journal of Emotional Abuse, 2(2/3), 7-23.

Türkileri, N. (2012). Ergenlerde sanal zorbalı: Nedenlerine ilişkin algılar, duygusal tepkiler ve baş etme yöntemleri ile zorbalık statüleri arasindaki ilişkiler. Hacettepe Üniversitesi Sosyal Bilimler Enstitüsü Psikoloji, Yüksek Lisans Tezi , Ankara.

Yaman,E.,Eroğlu,Y. ve Peker,A. (2011). Başaçıkma stratejileriyle okul zorbalığı ve sanal zorbalık. İstanbul:Kaknüs Yayınları.

\section{Kaynakça Bilgisi / Citation Information}

Arslan, S. ve Yeşilyurt, F. (2019). Ergenlerin sanal zorbalık düzeylerinin bazı değişkenler açısından incelenmesi. OPUS-Uluslararası Toplum Araştırmaları Dergisi, 11(18), 27-42. DOI: 10.26466/opus.515067 